\title{
Application of a liquid scintillation counter to the measurement of tracing radioactivity in experiments on suspended matter uptake in aquatic environments
}

\author{
R. El-Mrabet, G. Manjon ${ }^{1}$, J.M. Abril ${ }^{2}$ and R. Garcia-Tenorio ${ }^{1}$ \\ Departamento de Fisica Atomica, Molecular y Nuclear, Facultad de Fisica, \\ University of Seville, Apdo. 41060 Sevilla, Spain \\ ${ }^{1}$ Departamento de Fisica 2, University of Seville, ETSA, \\ Avda. Reina Mercedes s/n, 41012 Sevilla, Spain \\ ${ }^{2}$ Departamento de Fisica Aplicada 1, University of Seville, EUITA,

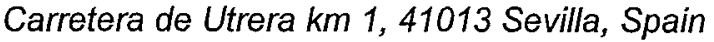

\begin{abstract}
The experiments on the study of the kinetic transfer coefficients of conservative and non-conservative radionuclides, in aquatic environments, need to determine radionuclide activity in large number of samples. Different radioactivity measurement techniques can be selected for analyses, but the liquid scintillation technique is preferred due to its easy sample treatment and its low time consumption. Samples are initially traced with a known activity of a selected radionuclide $\left({ }^{239} \mathrm{Pu},{ }^{241} \mathrm{Am}\right.$ or $\left.{ }^{99} \mathrm{Tc}\right)$. The transference of radionuclides, from the water to the suspended matter, is studied through the determination of the residual activity in aliquots of water sample, which are successively collected with time. In this work, we present the experimental procedures used for the ${ }^{239} \mathrm{Pu}$, ${ }^{241} \mathrm{Am}$ and ${ }^{99} \mathrm{Tc}$ activity measurement by liquid scintillation counting, using a Wallac Quantulus 1220 spectrometer. Results of the application of this technique to traced water samples are also shown in this study.
\end{abstract}

\section{INTRODUCTION}

The sorption and release kinetics of ${ }^{239} \mathrm{Pu},{ }^{241} \mathrm{Am}$ and ${ }^{99} \mathrm{Tc}$ by freshwater suspended particles were investigated to better identify the biogeochemical processes involved and to underestand the behaviour of these elements in aquatic environments. Time series data can be obtained from laboratory studies and can be analysed to study the transference of radionuclides activity from the water to the suspended matter. Tracing experiments were performed during a large time using natural aqueous suspensions from three aquatic systems (Gergal reservoir, the Guadalquivir river and the estuary of the Tinto river). Scientific literature lists many examples of experimental studies on uptake kinetics of dissolved radionuclides by suspended loads $[1,2]$. In this work we carry out a series of tracing experiments with ${ }^{239} \mathrm{Pu},{ }^{241} \mathrm{Am}$ and ${ }^{99}$ Tc by using environmental samples of unfiltered waters from three aquatic systems in the South of Spain. The experimental procedure ensures the preservation of environmental conditions. As the experimental method requires the determination of $\mathrm{Pu}, \mathrm{Am}$ and $\mathrm{Tc}$ activities in a large number of samples, it is important to select a measurement technique with low time consumption. Recently, liquid scintillation counting has been applied to $\mathrm{Pu}, \mathrm{Am}$ and Tc-isotopes. In works reported by [3], ${ }^{239+240} \mathrm{Pu}$ were simultaneously measured using a liquid scintillation counter PERALS ${ }^{\mathrm{TM}}$ and two extractive scintillators. Liquid scintillation technique is preferred because the tedious sample treatment required, e.g. for alpha spectrometry, is not necessary. The poor resolution of this technique (about $300 \mathrm{keV}$ ) will be not relevant in our measurements because a single alpha emitter, radiotracer, will be present in our samples.

This technique allows us to investigate newer and interesting aspects of the kinetic of the electrolytic reactions of $\mathrm{Pu}, \mathrm{Am}$ and $\mathrm{Tc}$ in fresh water ecosystems.

\section{MATERIAL AND METHODS}

\subsection{Sampling}

\footnotetext{
Water samples were collected from three different aquatic scenarios from the South of Spain. The first station was located the Gergal reservoir (NW from Seville). The second sample was collected in the Guadalquivir river, near the town of Seville. Waters were dark grey coloured by the effluents from factories and urban sewage in the surroundings. Finally a third sample was collected in the Tinto estuary, close to the Atlantic Ocean, during the low tide.
} 
At each sample site, we filled four 251 plastic bottles. Temperature, $\mathrm{pH}$ and electrical conductivity were measured just after collection. Samples were then carried to our laboratory and stored in dark during few hours. The tracing experiments generally begun at the following morning. We used a nephelometer to measure the suspended matter content. To convert NTU into $\mathrm{mg} / \mathrm{l}$ we weighted the dry matter obtained after filtering 501 of water by using a $0.45 \mu \mathrm{m}$ NUCLEOPORE filter. This calibration was repeated for each new environment. In Table 1 we show the temperature, $\mathrm{pH}$, the electrical conductivity, and the suspended matter content of collected samples, corresponding with natural conditions prevailing during the sampling.

Table 1. Temperature, pH, electrical conductivity and suspended matter content in water samples measured just after collection. Data can be considered as environmental conditions.

\begin{tabular}{lcccc}
\hline Environment & $\begin{array}{c}\text { Temperature } \\
\left({ }^{\circ} \mathrm{C}\right)\end{array}$ & PH & $\begin{array}{c}\text { Conductivity } \\
(\mathrm{mS})\end{array}$ & $\begin{array}{c}\text { Suspended matter } \\
(\mathrm{mg} / \mathrm{l})\end{array}$ \\
\hline Gergal reservoir & 27.1 & 8.35 & 0.46 & 7.37 \\
Guadalquivir river & 20.4 & 7.84 & 1.37 & 12.6 \\
Ttinto estuary & 19.4 & 7.86 & 66.25 & 7.62 \\
\hline
\end{tabular}

Hereafter the solid fraction will be considered that formed by suspended particles with a diameter larger than 0.45 $\mu \mathrm{m}$. The dissolved (more properly the filtered) fraction is formed by the water, dissolved elements and particles with smaller sizes. This is a practical assumption, since in most of the experimental studies this pore size is used to separate both fractions.

\subsection{Experimental procedure}

The objective of this work was to evaluate the uptake of ${ }^{239} \mathrm{Pu},{ }^{241} \mathrm{Am}$ and ${ }^{99} \mathrm{Tc}$ by suspended matter in environmental fresh waters. In each experience, a typical volume of 1.01 of water was transferred into a glass beaker. There, the sample was spiked with ${ }^{239} \mathrm{Pu},{ }^{241} \mathrm{Am}$ or ${ }^{99} \mathrm{Tc}$ and continuously stirred in to avoid any decantation of the suspended matter.

We followed the time evolution of the activity concentration in the dissolved phase by taking aliquots at different times after spiking. A typical volume of $45 \mathrm{ml}$ was selected for every aliquot. Suspended matter was removed by centrifugation ( 20 minutes at $4000 \mathrm{rpm}$ ). Then, $35 \mathrm{ml}$ of supernatant were transferred into a plastic container and acidulated with $1 \mathrm{ml}$ of $\mathrm{HNO}_{3}$ to avoid loses of plutonium by adsorption onto the container walls. Finally, $5 \mathrm{ml}$ of acidulated sample was transferred into a plastic vial and mixed with $15 \mathrm{ml}$ of liquid scintillation cocktail Pharmacia Optiphase 3.

Nephelometric measurements proved that the turbidity of the supernatant waters after centrifugation were similar to the measured ones in the filtrated fraction. Consequently, centrifugation is an efficient process to separate almost the same fraction that we could obtain by filtration. Filtration cannot be used as alternative technique to separate both fractions from each aliquote, since approximately some $10 \%$ in the case of the $\mathrm{Pu}$ was retained by the filter itself, as proved by filtrating distillate water spiked with $\mathrm{Pu}$ : Although centrifugation is our best choice, it is not a perfect process, and in some samples we got an incomplete separation, provoking some over-estimations of the specific activity in the dissolved (filtered) phase.

\subsection{Granulometric analysis and mineral composition study}

It is known $[4,5]$ that the kinetic transfer coefficient for direct sorption depends on the total available surface of particles per unit volume of solution, and on the concentration of active sites in the surface 
layer of solids. This last depends on the mineral composition, free edges, pores, coatings, etc. Thus, it is necessary to handle the particle size spectra and the mineral composition of natural occurring suspended loads to compare results from different environments and to fix the conditions of applicability of the derived coefficients.

A granulometric analysis of all the samples was carried out by using a Mater Sizer instrument with 100 size bands, from 0.01 to $1000 \mu \mathrm{m}$.

A Scanning electron microscope (SEM) was used to study the morphology of natural particles from all the samples. The SEM micrograph of the four samples revealed that the most common shape is the spherical one. We can appreciate some aggregation of particles owing to the preparation procedure. Saltcrystals are preent in most of the samples. Finally, the mineral composition was determined by X-ray diffraction (XRD). Some results are summarised in Table 2.

Table 2.- Results from granulometric and mineralogic analysis. Diameter $\phi_{1}$, in $\mu \mathrm{m}$, corresponds to the most frequent diameter, and $\phi_{2}$ is the diameter corresponding to particles with the highest percentage of volume. The specific surface area (S.S.A.) is computed assuming a density of $2.10 \mathrm{~g} \mathrm{~cm}^{-3}$ for all the solids.

\begin{tabular}{lccll}
\hline Environment & $\begin{array}{c}\text { Diameter } \phi_{1} \\
(\mu \mathrm{m})\end{array}$ & $\begin{array}{c}\text { Diameter } \phi_{2} \\
(\mu \mathrm{m})\end{array}$ & $\begin{array}{l}\text { S.S.A. } \\
\left(\mathrm{m}^{2} / \mathrm{g}\right)\end{array}$ & $\begin{array}{l}\text { Main mineralogical } \\
\text { composition }\end{array}$ \\
Gergal reservoir & 0.30 & 19 & 0.28 & $\mathrm{CaCO}_{3}$ Calcite, Muscovite \\
Guadalquivir river & 0.22 & 15 & 1.63 & $\mathrm{CaCO}_{3}$ Calcite \\
Ttinto estuary & 0.18 & 28 & 0.78 & $\mathrm{CaSO}_{4} 2 \mathrm{H}_{2} \mathrm{O}$, Bassanite \\
\hline
\end{tabular}

\subsection{Liquid scintillation counter}

A liquid scintillation spectrometer Wallac Quantulus 1220 TM was used for ${ }^{239} \mathrm{Pu},{ }^{241} \mathrm{Am}$ and ${ }^{99} \mathrm{Tc}$ activity measurements. The low background of the detector allows the measurement of low-level activities. Moreover, alpha and beta activity from the same sample can be measured simultaneous and separately (alpha and beta spectra) by using its pulse shape analyser (PSA) [6]. The PSA was optimised by measuring a ${ }^{239} \mathrm{Pu}$ and ${ }^{241} \mathrm{Am}$ standard samples, under the typical measurement conditions, at different values of the PSA threshold level. Results are shown in Fig.1, where alpha interference is plotted versus PSA level. Taking into account that alpha interference is defined as the fraction of alpha counts measured in the beta spectrum, a A PSA level of 55 was selected in our working conditions, because using higher values the alpha interference cannot be considered negligible and the counting efficiency decreases. In the ${ }^{99} \mathrm{Tc}$ activity measurements, it is not necessary to use the PSA.

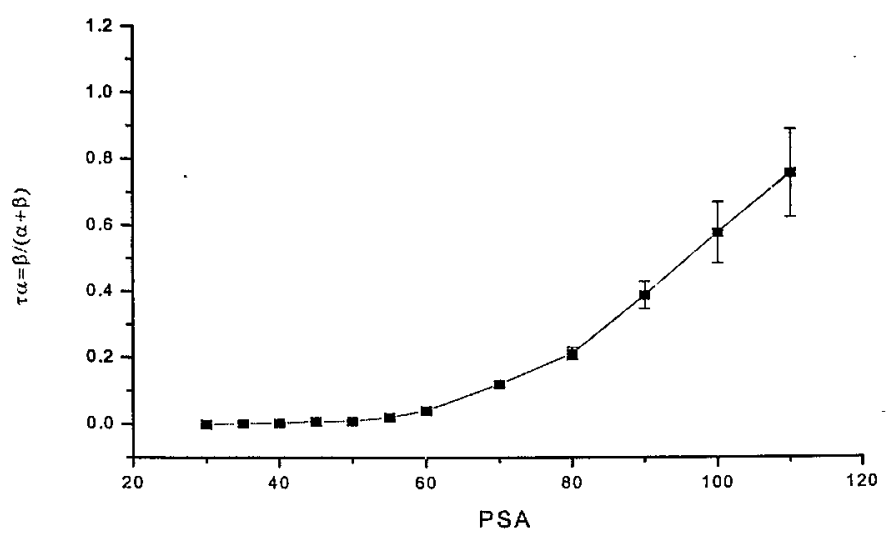

Figure 1.- Optimisation of the PSA of the Wallac Quantulus $1220^{\mathrm{TM}}$. Best results dor Pu and Am corresponds to PSA $=55$ 
When PSA is selected on, background counts are acquired in the beta spectrum, because ${ }^{40} \mathrm{~K}$ (a beta emitter) of vial walls is the main contributor to background of detector. We have to note that alpha/ beta separation is not totally efficient, and a part of the beta emissions can be counted in the alpha spectrum. This fraction is known as the beta interference and can be considered as the main contribution to the alpha background. Obviously, this beta interference decreases when increasing the PSA value. For this reason the PSA value was selected as the maximum value at which the alpha interference is still negligible.

On the other hand, we also studied the dependence of the alpha background with the volume of the sample. Always the distilled water/scintillator volume ratio was $1: 1$, and the sample volume ranged from 8 up to $20 \mathrm{ml}$. When the optimum PSA level was selected, the alpha background was similar in all cases. For that reason, the sample acceptance of the scintillator was considered as the main parameter for selecting the sample volume. For example, the scintillator used, the Wallac Optiphase Hisafe3, has a sample acceptance of $4 \mathrm{ml}$ of $2 \mathrm{M} \mathrm{HNO}_{3}$ in $10 \mathrm{ml}$ of scintillator. The samples obtained in our experiments can be considered as a $0.4 \mathrm{M} \mathrm{HNO}_{3}$ solution, but material originally dissolved in the environmental water could be present also in the sample to be measured and could reduce the sample acceptance of scintillator. This is the case of the Guadalquivir sample, where it is possible to appreciate the presence of colloids. For this reason, a volume of $5 \mathrm{ml}$ was selected for the aqueous phase, which was mixed with $15 \mathrm{ml}$ of scintillator. In these conditions, alpha background and alpha efficiency were determined in the different collected water samples. Alpha efficiency was determined spiking the $5 \mathrm{ml}$ of the water samples with known amounts of ${ }^{239} \mathrm{Pu},{ }^{241} \mathrm{Am}$ or ${ }^{99} \mathrm{Tc}$. Results are listed in Table 3 for $\mathrm{Pu}$ measurements. Alpha counting efficiency ranged from 0.67 up to 0.89 being no uniform, probably due to a different chenica! quenching of the sample. Background level ranged from $0.4 \mathrm{cpm}$ in the reservoir waters, to $0.8 \mathrm{cpm}$ for the Guadalquivir water. A higher level of $2.4 \mathrm{cpm}$ was measured in water collected from the Tinto estuary. This result can be attributed to the presence of natural alpha emitters in the sample [7].

Table 3. Counting characteristics of a Wallac Quantulus $1220^{\mathrm{TM}}$ in the case of ${ }^{239} \mathrm{Pu}$, using water samples collected in different environmental scenarios. LID is de detection limit, and MDA is the minimum detectable activity; counting time was 600 min in all the cases.

\begin{tabular}{lcccc}
\hline Environment & Efficiency & $\begin{array}{c}\text { Background } \\
(\mathrm{cpm})\end{array}$ & $\begin{array}{c}\text { MDA } \\
\left(\mathrm{Bq} \mathrm{liter}^{-1}\right)\end{array}$ & $\begin{array}{c}\text { LD } \\
(\mathrm{cpm})\end{array}$ \\
\hline Gergal & $0.67 \pm 0.01$ & $0.66 \pm 0.03$ & 0.23 & 0.047 \\
Guadalquivir & $0.89 \pm 0.03$ & $0.79 \pm 0.04$ & 0.19 & 0.051 \\
Tinto & $0.67 \pm 0.02$ & $2.36 \pm 0.06$ & 0.44 & 0.089 \\
\hline
\end{tabular}

\section{RESULTS AND DISCUSSION}

In figures $2,3,4,5$ and 6 we show the time evolution of ${ }^{239} \mathrm{Pu},{ }^{241} \mathrm{Am}$ and ${ }^{99} \mathrm{Tc}$ activities in the dissolved phase corresponding to the four series of experiments. Measured values are represented with error bars. From Fig. 2, 3, 4 and 5, in logarithmic scale, three different regions characterised by different slopes can be distinguished: first region corresponds to a fast reaction, lasting for few minutes, during which time up to $30 \%$ of dissolved $\mathrm{Pu}$ or Am is transferred onto suspended solids. This corresponds to a fast physical-adsorption reaction ( $\mathrm{Pu}$ or $\mathrm{Am}$ is fixed by coulombian forces onto the external free surface of particles); in second region, other reaction governs the $\mathrm{Pu}$ or Am uptake during 10-20 hours time, transferring up to $30 \%$ of remaining $\mathrm{Pu}$ in dissolved form. This reaction corresponds to plysical adsorption onto the inner surface of pores and free-edges, and to the formation of reversible unions of a different nature and/or strength. In third region, the uptake (up to $50 \%$ of the remaining Pu or Am in solution) continues during several days (the duration of the experiments was too short to allow a conclusion concerning the final course of the reaction). This reaction may correspond to a slower process in which previously adsorbed $\mathrm{Pu}$ or $\mathrm{Am}$ is transferred into the inner matrix of the particles or forms other non-reversible unions. 

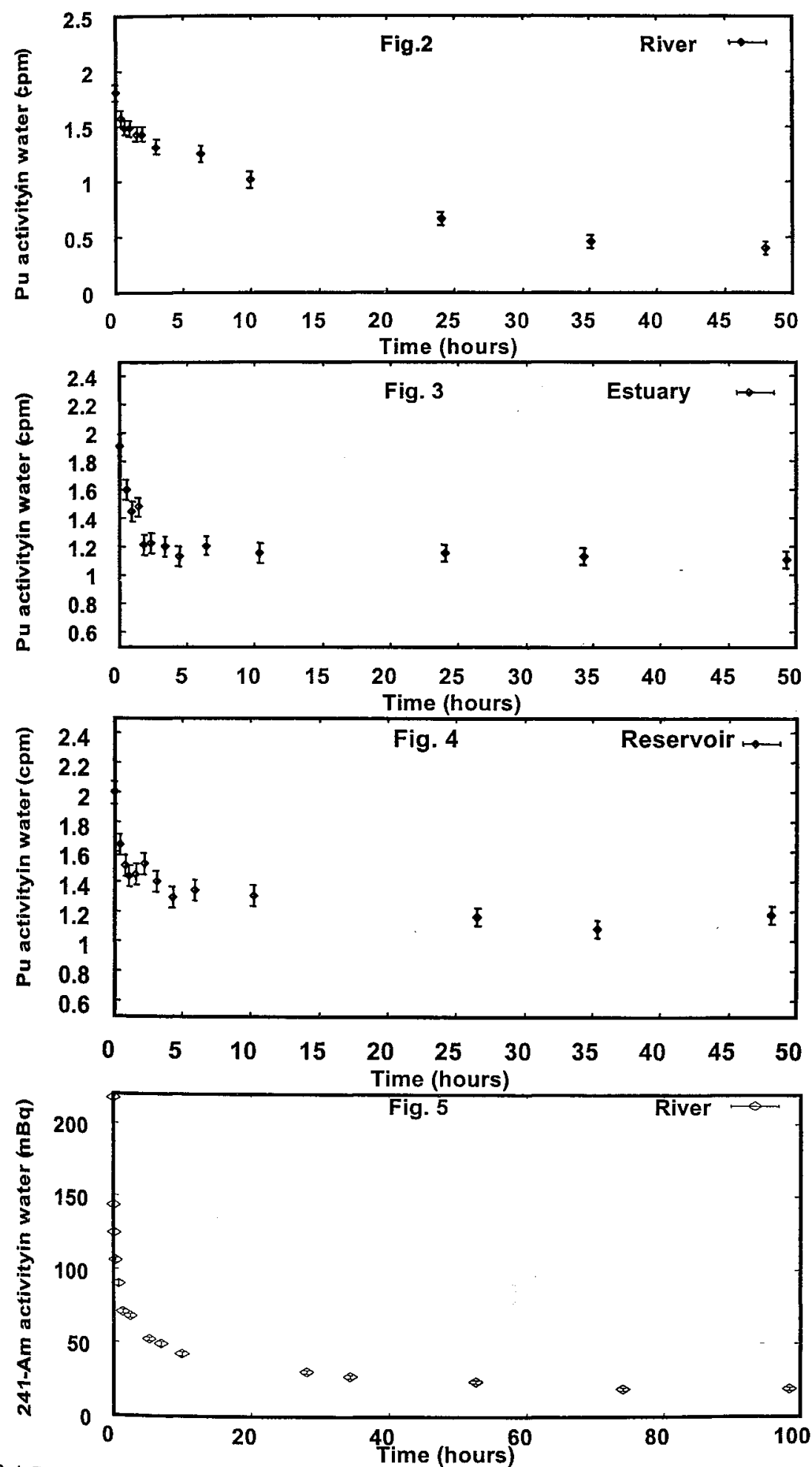

Fig. $(2,3,4,5)$ : Time evolution of 239-Pu and 241-Am activities (in cpm and $\mathrm{mBq}$ ) in the dissolved phase corresponding to the four series of experiments on 239-Pu and 241-Am uptake (non-conservartive radiotracers) in natural aqueous suspensions. 


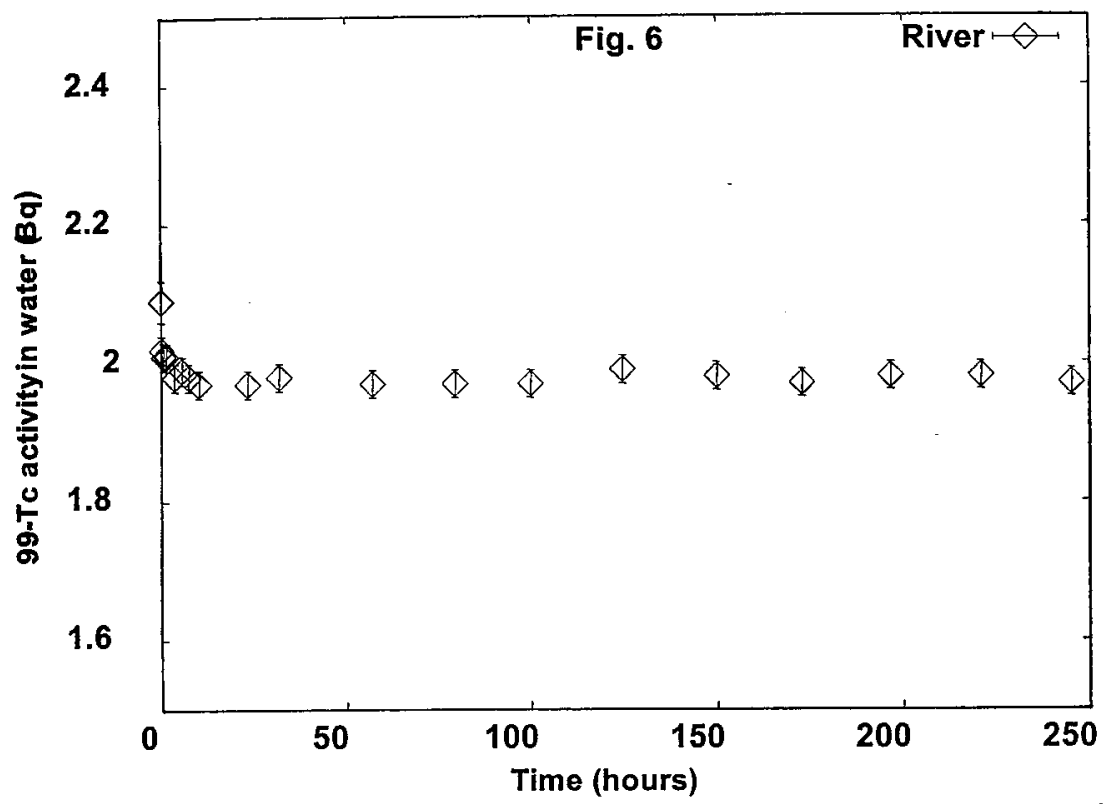

Fig. 6: Time evolution of 99-Tc activities (in $\mathrm{mBq}$ ) in the dissolved phase corresponding to the serie of experiments on conservative radiotracer (99-Tc) uptake in natural aqueous suspensions of unfiltered waters from Guadalquivir river.

From Fig.6, the 99-Tc is considered as conservative radionuclide, the fraction of the 99-Tc absorbed by the suspended matter is negligible.

\section{CONCLUSIONS}

In this work we applied a useful experimental procedure to study the uptake of $\mathrm{Pu}, \mathrm{Am}$ and $\mathrm{Tc}$ by natural aqueous suspensions, based on the use of liquid scintillation technique.

\section{Acknowledgements}

This work has been partially supported by $\mathrm{I}+\mathrm{D}$ contract with ENRESA, Spain.

\section{References}

1. Laissaoui A., Abril J.M., Periáñez R., García León M., García Montaño E. Journal of Radioanalytical and Nuclear Chemestry. 237 (1-2) (1998) 55-61.

2. R. El Mrabet, J.M Abril, G. Manjón and R. García Tenorio. Water Research (2001) (accepted for publication).

3. J. Auplais Journal of Radioanalytical and Nuclear Chemistry 218 (1997) 201-207.

4. J.M. Abril Journal of Environmental Radioactivity. 41 (1998a)307-324, Part I: theory development

5. J.M. Abril Journal of Environmental Radioactivity. 41 (1998b) 325-342, Part II: applications

6. G. Manjón, I. Vioque, H. P. Moreno, R. García-Tenorio and M. García-León. Applied Radiation Isotopes. 48 (1997) 535-540

7. H. P. Moreno, I. Vioque, G. Manjón and R. García-Tenorio. Czechoslovak Journal of Physics (1999) (accepted for publication) 